\title{
Competence frameworks prototyping for project team members
}

\author{
Eryk Szwarc, Koszalin University of Technology, Poland, eryk.szwarc@tu.koszalin.pl
}

\begin{abstract}
A team of competent employees is one of many factors that determine the success of a project. Many approaches have been described in the literature to help decision-makers plan competence frameworks to complete project portfolios. Few of them take into account the disruptions that may occur during the project realization caused, for example, by employee absenteeism, employee fluctuations, etc. In this area, there is still a lack of solutions (methods and implementing them IT environments) that could be used to support decision-makers in planning so-called competence frameworks robust to the disruptions, that guarantee the completion of planned project portfolios. The possibility of the practical application of the proposed method was illustrated in the example of a university.
\end{abstract}

Keywords: Project, Competence framework, Planning, Disruption, Robustness

\section{Introduction}

Every project is carried out in an uncertain and constantly changing environment, dominated by technological and organizational innovations, growing competition, employee turn-over, legislative changes, etc. This causes unforeseen (undesirable, unplanned) events to occur during project realization that can be the source of project failure. As a consequence, decisions regarding establishing project teams are subject to uncertainties related to temporary or permanent unavailability of resources (e.g., employees), delays in starting activities, changes in activity durations, etc. In other words, during the planning of project teams, it is necessary to take into account the unforeseen events that disrupt their realization, especially those that pose a risk to the project deadlines (Söderholm, 2008).

Decision makers are usually unable to predict the appearance moment of the disruptions (e.g., which employee will be absent and in what time frame, which materials will be delivered with what delay, etc.) (Collier \& Lambert, 2018). Therefore, in the following discussion, we will refer only to such disruptions whose type is known to the decision-maker, but the moment of their occurrence and duration are unknown. This means that the probability of disruption appearance is unknown. A disruption can be understood as a:

- temporary absence of any employee (e.g., sick leave, inability to perform duties, etc.) or permanent unavailability of an employee (e.g., change of employer, death, etc.),

- change in the customer's requirements during the project realization, resulting in the need to perform additional, unplanned activities, etc.

The high rate of sick leave in 2020 (due to the coronavirus pandemic) (ec.europa.eu, 2021) and the employee turnover that has persisted for several years (Hom, Lee, Shaw \& Hausknecht, 2017) result in a constant search for new methods to reduce the effects of employee loss during the project realization. One type of disruption related to absenteeism was further assumed, which can: 


\section{Issues in Information Systems}

Volume 22, Issue 1, pp. 188-199, 2021

- concern every member of the team,

- occur at any time during the project,

- last any amount of time.

Section 2 presents a closer look at the current state of research on existing methods to ad-dress the effects of employee absenteeism. Section 3 formulates the competence framework planning problem that are robust to selected disruptions. Section 4 presents a model to search for competence frameworks that are robust to employee absenteeism. The demonstrated ex-ample in section 5 illustrates the problem solution. The final section presents conclusions as well as directions for further research.

\section{Literature review}

The most frequently observed reaction to employee absenteeism is an attempt to look for a modification of the realized assignment of activities (so-called re-allocation), which will allow a continuation of the project (Klimek \& Łebkowski, 2011). However, the possibility of carrying out appropriate changes depends, among other things, on the competencies of the available employees. In a particular case, it may turn out that due to insufficient competence of the remaining employees, it is not possible to carry out the relevant changes that would enable to continue of the activity.

An alternative to the presented reactive (situational) approach is the concept of proactive planning called pre-situational management (Dück, Ionescu, Kliewer \& Suhl, 2012; Ionescu \& Kliewer, 2011). It comes down to developing in advance (before the start of the project) patterns (variants) of action (repair plans) in the event of the occurrence of a known disruptions. These could be variations on project plans, activity assignments to employees, etc.

Therefore, in the context of competencies, pre-situational planning comes down to the preparation of a team characterized by the so-called competence framework that guarantees the changes in the assignment of activities in the event of disruptions (Szwarc, Bocewicz, Banaszak \& Wikarek, 2019; Szwarc, Wikarek, Gola, Bocewicz \& Banaszak, 2020). Providing such a guarantee is seen in two approaches: preparation of employee's competencies under so-called cross-training (Olivella \& Nembhard, 2016) or the use of socalled employee reserves that increase the competence capabilities of employees in the event of disruptions (Moudani \& Mora-Camino, 2010; Ingels \& Maenhout, 2015; Malen \& Vaaler, 2017). These approaches have been applied in the works of (Szwarc, Bocewicz, Bach-Dąbrowska \& Banaszak, 2019; Szwarc \& Wikarek, 2020; Bocewicz, Szwarc, Wikarek, Nielsen \& Banaszak, 2021), which present a model and a method providing an estimation in what per-centage the competence framework is robust to disruptions. The measure of robustness to disruptions is the ratio of the number of variants of the given types of disruptions for which there is an assignment of activities to employees guaranteeing the execution of the given plan to all possible variants of disruptions. It is assumed that this is the value of a linear function, in the domain of real numbers, within range from 0 to 1, where:

- value of 0 means no robustness, i.e., for each case of absenteeism, there is no activity allocation that guarantees timely execution of the given plan,

- value of 1 means full robustness, i.e., for each case of absenteeism, there is an activity allocation that guarantees timely execution of the given plan.

The presented robustness measure was used to solve the problem of planning competence frameworks robustness to selected disruptions. 


\section{Problem}

The problem under consideration is defined as follows: The project (the set of activities) is given, the available number of employees is known (team of employees with a given competence framework). The assignment of activities to individual employees is known. A set of disruptions that may delay project completion is identified. The expected robustness of the competence framework to selected disruptions is known. The problem comes down to solving two subproblems:

- assessment (analysis) of the robustness of the competence framework to a given disruption,

- searching for competence framework of the team of employees executing the project portfolio, which guarantee the expected robustness to the given disruptions.

In order to solve the problem, a reference model was built for the problem of planning competence frameworks robust to selected disruptions. The assumed declarative nature of the model allows us to formulate the problem of planning robust competence frameworks in the form of the so-called Constraints Satisfaction Problem (CSP). The CSP solution comes down to the search for such values of decision variables that meet a number of specific requirements (limitations) that make up the formulated problem.

\section{Reference model and planning method of competence framework robust to disruptions}

A declarative modeling paradigm has been used to formally describe the considered problems of analysis and synthesis of competence frameworks robust to disruptions. For this purpose, the following reference model is introduced:

$\underline{\text { Sets: }}$

$\overline{Z:} \quad$ a set of operations carried out under the project portfolio $Q: Z=\left\{Z_{1}, \ldots, Z_{n}\right\}$,

$Z^{\lambda}$ : a set of additional operations: $Z^{\lambda}=\left\{Z_{n+1}, \ldots, Z_{n+\lambda}\right\}$ (project portfolio disruption),

$\mathcal{P}: \quad$ a set of employees: $\mathcal{P}=\left\{P_{1}, \ldots, P_{m}\right\}$,

$U_{\omega}: \quad$ set of $\omega$-element variants of employee absenteeism: $U_{\omega}=\left\{\left\{u_{1}, \ldots, u_{i}, \ldots, u_{\omega}\right\} \mid u_{i} \in\{1, \ldots, m\}\right\}$,

$L P_{\omega}$ : a subset of the set of $U_{\omega}\left(L P_{\omega} \subseteq U_{\omega}\right)$ defining absenteeism cases for which the competence framework is robust to absenteeism of employees $\omega$ and assigning additional activities $\lambda$.

$\Theta: \quad$ single variant of employee's absenteeism $\omega, \Theta \in U_{\omega}$.

\section{Parameters:}

$n: \quad$ number of operations carried out in the project portfolio $\mathcal{Q}(n \in \mathbb{N})$,

$q_{i}$ : number of operation activities $Z_{i}$,

$m: \quad$ number of employees in team $\mathcal{P}(m \in \mathbb{N})$,

$\omega: \quad$ number of absent members in team $\mathcal{P}(\omega \in \mathbb{N}), \omega<m$,

$\lambda: \quad$ number of additional operations $(\lambda \in \mathbb{N})$, specified in the set $Z^{\lambda}$,

$l_{i}$ : duration of the operation activity $Z_{i}$,

$y_{i}: \quad$ start of the operation activity $Z_{i}$,

$\varphi_{i}$ : number of employees required for the operation realization $Z_{i}$,

$s_{k}$ : minimum working hours of employee $k\left(s_{k} \in \mathbb{N}\right)$,

$z_{k} \quad$ maximum working time of employee $k\left(z_{k} \in \mathbb{N}\right)$,

$w_{i}$ : $\quad$ set of operations excluding the operation $Z_{i}, w_{i} \subseteq Z$,

$R^{*}: \quad$ expected robustness of the competence framework, $R^{*} \in[0,1]$.

Decision variables:

$G: \quad$ competence framework given by the matrix $G=\left[g_{k, i}\right]_{k=1 \ldots m ; i=1 \ldots n+\lambda}$, where $g_{k, i} \in\{0,1\}$ : 


$$
g_{k, i}=\left\{\begin{array}{cc}
1 & \text { when employee } P_{k} \text { has competencies to perform the operation } Z_{i} \\
0 & \text { in other cases }
\end{array}\right.
$$

$R_{\omega}^{\lambda}$ : the measure of the robustness of the competence framework $G$ to disruptions defined by $U_{\omega} \mathrm{i} Z^{\lambda}$,

$G^{\Theta}$ : competence frameworks taking into account absenteeism of employees specified in the set $\Theta$ :

where $g_{k, i}^{\Theta} \in\{0,1\}$ :

$$
G^{\Theta}=\left[g_{k, i}^{\Theta}\right]_{k=1 \ldots m ; i=1 \ldots n+\lambda},
$$

$$
g_{k, i}^{\Theta}=\left\{\begin{array}{cc}
1 & \text { when } k \notin \Theta \mathrm{i} P_{k} \text { is competent to perform the operation } Z_{i}, \\
0 & \text { in other cases }
\end{array},\right.
$$

$X: \quad$ allocation of activities of operations from portfolio $\mathcal{Q}$ to employees of team $\mathcal{P}, X=$ $\left[x_{k, i}\right]_{k=1 \ldots m ; i=1 \ldots n+\lambda}$, where: $x_{k, i} \in\left\{0.1, \ldots, q_{i}\right\}$ specifies the number of actions of the operation $Z_{i}$, which is carrying out by an employee $P_{k}$,

$X^{\Theta}$ : allocation in a situation of absenteeism of employees defined in the set $\Theta: X^{\Theta}=$ $\left[x_{k, i}^{\Theta}\right]_{k=1 \ldots m ; i=1 \ldots n+\lambda}$, where: $x_{k, i}^{\Theta} \in\left\{0.1, \ldots, q_{i}\right\}$ defines the number of activities of operations $Z_{i}$, in the event of absenteeism of employees defined in the set $\Theta$,

$c^{\Theta}$ : variable determining whether an allocation $X^{\Theta}$ exists that guarantees realization of the set operations $Z \cup Z^{\lambda}$ within the given deadline. The value of a variable $c^{\Theta} \in\{0,1\}$ depends on partial auxiliary variables $c_{1, i}^{\Theta}, c_{2, k}^{\Theta}, c_{3, k}^{\Theta}$ determining whether the following constraints (1)-(12) are fulfilled.

Constraints:

1. The elements $g_{k, i}^{\Theta}$ of the matrix $G^{\Theta}$ that characterize employee absenteeism $P_{k}(k \in \Theta)$ take the values 0 :

$$
\mathrm{g}_{\mathrm{k}, \mathrm{i}}^{\Theta}=\left\{\begin{array}{cc}
\mathrm{g}_{\mathrm{k}, \mathrm{i}} & \text { when } \mathrm{k} \notin \Theta \\
0 & \text { when } \mathrm{k} \in \Theta
\end{array}\right.
$$

2. Activities of operations $Z$ are performed only by employees with appropriate competencies:

$$
x_{k, i}^{\Theta} \leq q_{i} \cdot g_{k, i}^{\Theta} \text {, for } k=1 \ldots m ; i=1 \ldots n+\lambda ; \forall \Theta \in U_{\omega}
$$

3. At any given time, the employee performs at most one activity:

$$
\begin{gathered}
\neg\left(\left(y_{\alpha, a}+l_{\alpha} \leq y_{\beta, b}\right) \vee\left(y_{\beta, b}+l_{\beta} \leq y_{\alpha, a}\right)\right) \Rightarrow\left(x_{k, \alpha}^{\Theta} \cdot x_{k, \beta}^{\Theta}=0\right) \\
\alpha, \beta=1 \ldots n ; k=1 \ldots m ; a=1 \ldots q_{\alpha} ; b=1 \ldots q_{b} \forall \Theta \in U_{\omega}
\end{gathered}
$$

4. Operations $Z$ are performed by teams $\varphi_{i}$ of competent employees:

$$
\begin{gathered}
\left(\sum_{k=1}^{m} x_{k, i}^{\Theta}=q_{i} \cdot \varphi_{i}\right) \Leftrightarrow\left(c_{1, i}^{\Theta}=1\right), \text { for } i=1 \ldots n ; \forall \Theta \in U_{\omega} \\
\left(\sum_{k=1}^{m} x_{k, i}^{\Theta} \geq q_{i} \cdot \varphi_{i}\right) \Leftrightarrow\left(c_{1, i}^{\Theta}=1\right), \text { for } i=n \ldots n+\lambda ; \forall \Theta \in U_{\omega} \\
\forall_{\alpha \in H} \exists_{k \in\{1 \ldots m\}}^{! ! \varphi_{i}}\left(x_{k, i}^{\Theta}=q_{i}\right) \wedge\left[\neg\left(\left(\alpha+l_{i} \leq y_{\beta, b}\right) \vee\left(y_{\beta, b}+l_{\beta} \leq \alpha\right)\right) \Rightarrow\left(x_{k, \beta}^{\Theta}=0\right)\right], \\
\text { for } \beta=1 \ldots n ; i=n \ldots n+\lambda ; b=1 \ldots q_{b} ; \forall \Theta \in U_{\omega}
\end{gathered}
$$

where: $\exists^{!} a-$ existential quantifier: "exactly $a$ elements exist".

5. The workload of the $k$-th employee is equal to or greater than the minimum working hours $s_{k}$ : 


\section{Issues in Information Systems}

Volume 22, Issue 1, pp. 188-199, 2021

$$
\left(\sum_{\mathrm{i}=1}^{n+\lambda} x_{k, i}^{\Theta} \cdot l_{i} \geq s_{k}\right) \Leftrightarrow\left(c_{2, k}^{\Theta}=1\right), \text { for } k=\{1 \ldots m\} \backslash \Theta ; \forall \Theta \in U_{\omega}
$$

6. The workload of the $k$-th employee is not greater than the maximum working time $z_{k}$ :

$$
\left(\sum_{\mathrm{i}=1}^{n+\lambda} x_{k, i}^{\Theta} \cdot l_{i} \leq z_{k}\right) \Leftrightarrow\left(c_{3, k}^{\Theta}=1\right) \text {, for } k=\{1 \ldots m\} \backslash \Theta ; \forall \Theta \in U_{\omega}
$$

7. Realization of mutually exclusive activities:

$$
\left(Z_{b} \in w_{i}\right) \Rightarrow\left(x_{k, i}^{\Theta} \cdot x_{k, b}^{\Theta}=1\right), \text { for } i=1 \ldots n+\lambda, k=1 \ldots m ; \forall \Theta \in U_{\omega}
$$

8. Robustness $R_{\omega}^{\lambda}$ is calculated as the ratio of the number of variants $\left|L P_{\omega}\right|$, for which the competence framework is robust to absenteeism $\omega$ of employees and ordering $\lambda$ additional activities to all possible variants of disruptions $\left(\left|U_{\omega}\right|\right)$.

$$
\begin{gathered}
R_{\omega}^{\lambda}=\frac{\left|L P_{\omega}\right|}{\left|U_{\omega}\right|} \geq R^{*} \\
L P=\sum_{\Theta \in U_{\omega}} c^{\Theta} \\
c^{\Theta}=\prod_{i=1}^{n+\lambda} c_{1, i}^{\Theta} \prod_{k=1}^{m} c_{2, k}^{\Theta} \prod_{k=1}^{m} c_{3, k}^{\Theta}
\end{gathered}
$$

The proposed model includes a set of decision variables (describing: competence framework, the measure of its robustness, assignment of activities to employees), discrete domains of decision variables, as well as a set of constraints (relations connecting decision variables) characterizing the requirements for competence framework and realization of planned activities. Due to the method of model specification, limited to the definition of decision variables, domains of variables and constraints imposed on subsets of variables, the considered analysis and synthesis problems belong to the class of Constraints Satisfaction Problems (CSP), which were implemented in the environment IBM ILOG CPLEX.

The method illustrated in the Figure 1, supporting the planning of competence frameworks in terms of searching for competence frameworks robust to selected disruptions (employee absenteeism), enables the analysis of the robustness of the adopted competence framework (stage 1 of the method).

If the result of the robustness analysis is unsatisfactory, the method allows (step 2 of the method) to support the search for a redundant competence framework (what competencies should be acquired by which employee), which will be robust to a given degree (e.g., equal to 1).

In case of lack of competence frameworks of desired robustness, the method allows indicating the competencies that should be characterized by newly hired employees in order to obtain the desired robustness (stage 3 of the method). It is worth noting that after verifying the method (Szwarc et al, 2020; Bocewicz et al, 2021), the obtained results do not provide the number of new employees. It is therefore proposed to extend the model by determining the average number of competencies per employee. The next section presents solutions to the problem, taking into account the number of new employees with competencies that provide the expected robustness. 


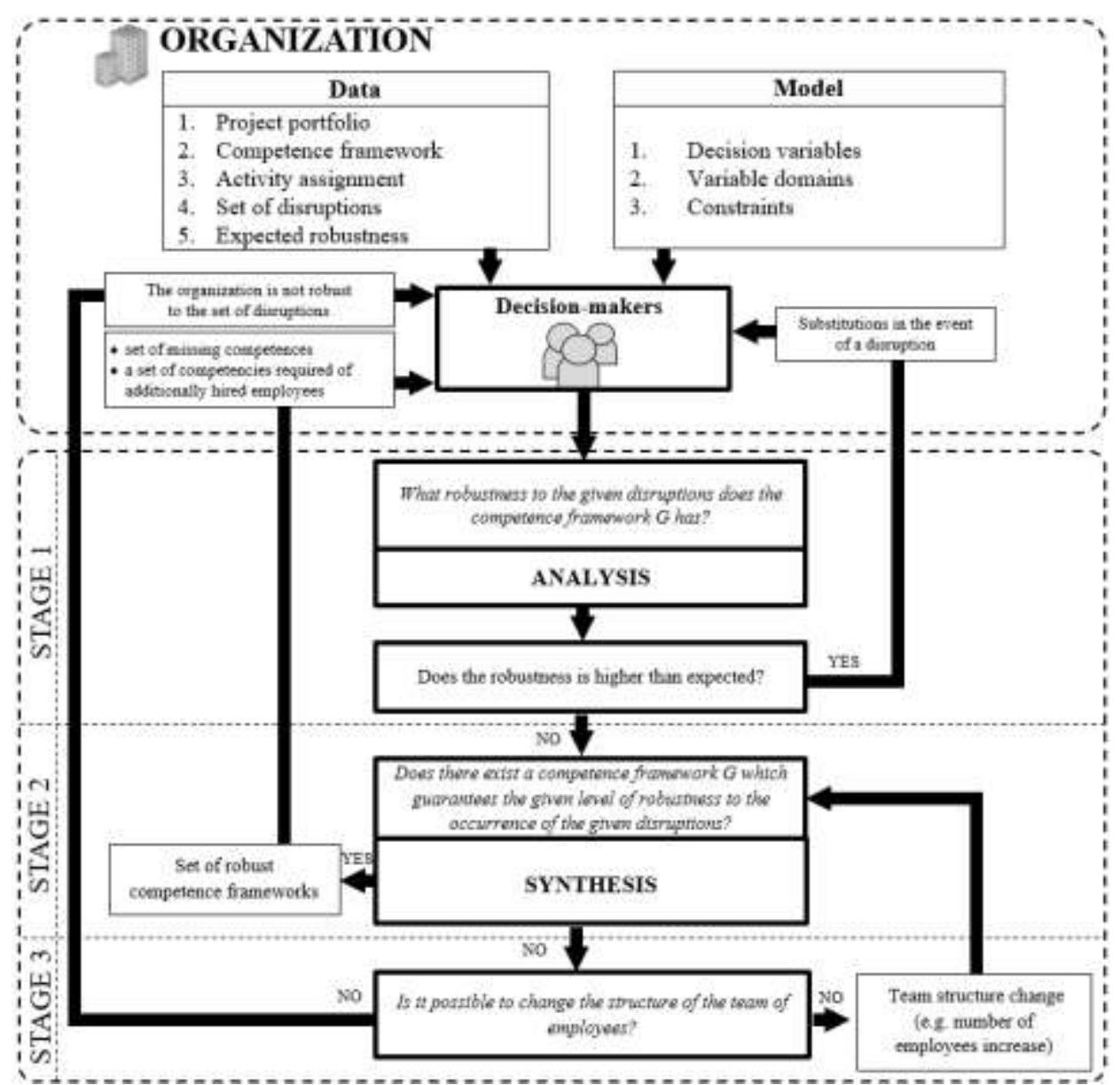

Figure 1. Method for the planning of competence frameworks robust to disruptions

\section{Example}

Data obtained from the Faculty of Electronics and Computer Science of Koszalin University of Technology (hereinafter FECS) were accepted. FECS carries out 214 operations (hereinafter subjects): $Z=$ $\left\{Z_{1}, Z_{2}, \ldots, Z_{214}\right\}$ (lectures, exercises, laboratories, projects, seminars). For each subject, there is the number of class groups $q_{i}$, the number of hours $l_{i}$ per group, the number of employees required to complete the subject. Data on the set of subjects $Z$ conducted at FECS are illustrated in the Table 1.

Table 1. Set of subjects $Z$ for FECS

\begin{tabular}{|l|c|c|c|}
\hline \multicolumn{1}{|c|}{$\boldsymbol{Z}_{\boldsymbol{i}}$} & $\boldsymbol{q}_{\boldsymbol{i}}$ & $\boldsymbol{l}_{\boldsymbol{i}}$ & $\boldsymbol{\varphi}_{\boldsymbol{i}}$ \\
\hline$Z_{1}:$ History of technology & 16 & 5 & 1 \\
\hline$Z_{2}:$ History of technology 2 & 5 & 5 & 1 \\
\hline$Z_{3}:$ Inventics & 12 & 5 & 1 \\
\hline$Z_{4}:$ Economic Sciences & 9 & 5 & 1 \\
\hline$Z_{5}:$ Fundamentals of mathematical analysis & 20 & 5 & 1 \\
\hline$\ldots$ & $\ldots$ & $\ldots$ & $\ldots$ \\
\hline$Z_{74}:$ Programming in .NET environment & 21 & 5 & 1 \\
\hline$\ldots$ & $\ldots$ & $\ldots$ & $\ldots$ \\
\hline$Z_{213}:$ Distributed information systems & 6 & 5 & 1 \\
\hline$Z_{214}:$ Artificial intelligence methods & 6 & 5 & 1 \\
\hline
\end{tabular}




\section{Issues in Information Systems}

Volume 22, Issue 1, pp. 188-199, 2021

FECS has 49 employees. Their competencies (education, academic achievements, knowledge, etc.) are known, which define which classes they can teach. Table 2 shows the competence framework $G$ of a team of employees $\mathcal{P}$. Due to data protection requirements, the processed data has been pseudonymized. The cell values determine the values of the variables $g_{k, i}$ of the framework $G$ and mean:

- 1 - employee $P_{k}$ has competencies to teach the subject $Z_{i}\left(g_{k, i}=1\right)$,

- $\{0,1\}$ - employee $P_{k}$ does not have the competencies to teach the subject $Z_{i}$ but can acquire them $\left(g_{k, i} \in\right.$ $\{0,1\})$,

- 0 - employee $P_{k}$ does not have the competencies to teach the subject $Z_{i}$ and cannot acquire them $\left(g_{k, i}=\right.$ $0)$.

Table 2. Competence framework $G$ of FECS employees (file "G_base.xlsx" at https://github.com/erykszw/WEiI)

\begin{tabular}{|c|c|c|c|c|c|c|c|c|c|c|c|c|c|c|}
\hline$X$ & 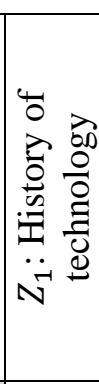 & 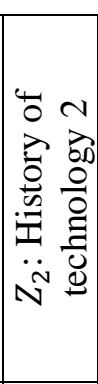 & 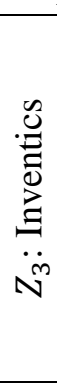 & 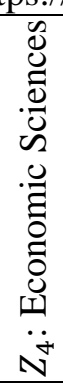 & 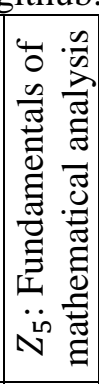 & 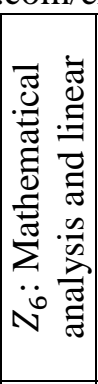 & $\vdots$ & 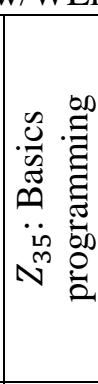 & 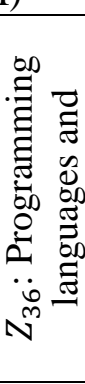 & $\vdots$ & $\vdots$ & 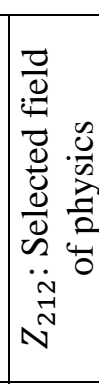 & 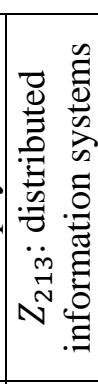 & 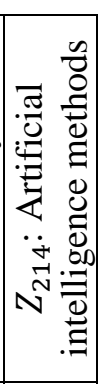 \\
\hline$P_{1}:$ Perz & 1 & 1 & 0 & 0 & 0 & 0 & $\ldots$ & 0 & 0 & $\ldots$ & $\ldots$ & 1 & 0 & 0 \\
\hline$P_{2}:$ Lejman & 0 & 0 & 0 & 0 & 0 & 0 & $\ldots$ & 1 & 1 & $\ldots$ & $\ldots$ & 0 & 0 & 0 \\
\hline$P_{3}:$ Matuszek & 0 & 0 & 0 & 0 & 0 & 0 & $\ldots$ & 0 & 0 & $\ldots$ & $\ldots$ & 0 & 0 & 0 \\
\hline & $\ldots$ & $\ldots$ & $\ldots$ & $\ldots$ & $\ldots$ & $\ldots$ & $\ldots$ & $\ldots$ & $\ldots$ & $\ldots$ & $\ldots$ & $\ldots$ & $\ldots$ & \\
\hline$P_{24}:$ Schulz & 1 & 1 & 0 & 0 & 0 & 0 & $\ldots$ & 0 & 0 & $\ldots$ & $\ldots$ & 1 & 0 & 0 \\
\hline$P_{25}:$ Olesinski & 1 & 1 & 0 & 0 & 0 & 0 & $\ldots$ & 0 & 0 & $\ldots$ & $\ldots$ & 0 & 0 & 0 \\
\hline$\ldots$ & $\ldots$ & $\ldots$ & $\ldots$ & $\ldots$ & $\ldots$ & $\ldots$ & $\ldots$ & $\ldots$ & $\ldots$ & $\ldots$ & $\ldots$ & $\ldots$ & $\ldots$ & 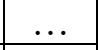 \\
\hline$P_{47}:$ Wingert & 0 & 0 & 0 & 1 & 0 & 0 & $\ldots$ & 0 & 0 & $\ldots$ & $\ldots$ & 0 & 0 & 0 \\
\hline$P_{48}:$ Tkacz & 0 & 0 & 0 & 0 & 0 & 0 & $\ldots$ & 0 & 0 & $\ldots$ & $\ldots$ & 0 & 0 & 0 \\
\hline$P_{49}:$ Klima & 0 & 0 & 0 & 0 & 0 & 0 & $\ldots$ & $\{0,1\}$ & 0 & $\ldots$ & $\ldots$ & 0 & 0 & 0 \\
\hline
\end{tabular}

The lower $\left(s_{k}\right)$ and upper $\left(z_{k}\right)$ working time limits for individual employees $\mathcal{P}$ are known (Table 3$)$.

In most cases, the lower limit is determined by the statutory working hours of an academic employee (e.g., professor 180 hours, assistant professor and university professor 240 hours, lecturer 360 hours), and the upper limit is twice the value of this number of hours. For example, $P_{1}$ : Perz has a minimum of $s_{k}=180$ hours and a maximum of $z_{k}=360$ hours, $P_{2}$ : Lejman has $s_{k}=360$ hours and $z_{k}=600$ hours, etc. It is assumed that the working hours of individual employees do not change over time.

The realized allocation of subjects $X$ is illustrated in the Table 4. This allocation meets the following requirements:

- the subjects $Z_{i}$ are realized only by competent employees,

- the working time limits $\left(s_{k}, z_{k}\right)$ cannot be exceeded. 


\section{Issues in Information Systems}

Volume 22, Issue 1, pp. 188-199, 2021

Table 3. Working time limits for FECS employees

\begin{tabular}{|c|c|c|c|c|c|c|c|c|c|c|c|}
\hline & $s_{k}$ & $z_{k}$ & & $s_{k}$ & $z_{k}$ & & $s_{k}$ & $z_{k}$ & & $s_{k}$ & $z_{k}$ \\
\hline$P_{1}:$ Perz & 180 & 360 & $P_{14}:$ Bajer & 240 & 480 & $P_{27}:$ Ledwon & 240 & 500 & $P_{40}:$ Firlej & 240 & 480 \\
\hline$P_{2}:$ Lejman & 360 & 600 & $P_{15}:$ Wasinski & 360 & 600 & $P_{28}:$ Kowal & 360 & 600 & $P_{41}:$ Tobolski & 180 & 360 \\
\hline$P_{3}:$ Matuszek & 180 & 360 & $P_{16}:$ Jaros & 180 & 360 & $P_{29}:$ Kaniowski & 190 & 480 & $P_{42}:$ Rojewska & 340 & 600 \\
\hline$P_{4}:$ Rzepka & 180 & 360 & $P_{17}:$ Zalewski & 360 & 600 & $P_{30}:$ Baczewski & 240 & 480 & $P_{43}:$ Kawalec & 240 & 480 \\
\hline$P_{5}:$ Dunajski & 360 & 600 & $P_{18}:$ Bugajski & 180 & 360 & $P_{31}:$ Warchol & 240 & 480 & $P_{44}:$ Miler & 20 & 120 \\
\hline$P_{6}:$ Polanski & 120 & 240 & $P_{19}:$ Knopik & 240 & 480 & $P_{32}:$ Ferens & 180 & 400 & $P_{45}:$ Korzen & 50 & 120 \\
\hline$P_{7}:$ Pieczara & 128 & 360 & $P_{20}:$ Zarzycki & 240 & 480 & $P_{33}:$ Mann & 345 & 600 & $P_{46}:$ Błaszczak & 20 & 120 \\
\hline$P_{8}:$ Zaorski & 240 & 480 & $P_{21}:$ Polus & 120 & 240 & $P_{34}:$ Marczak & 240 & 480 & $P_{47}:$ Wingert & 30 & 120 \\
\hline$P_{9}:$ Rek & 240 & 480 & $P_{22}:$ Krygier & 360 & 600 & $P_{35}:$ Lakoma & 180 & 360 & $P_{48}:$ Tkacz & 150 & 300 \\
\hline$P_{10}:$ Zajkowski & 360 & 600 & $P_{23}:$ Pakula & 120 & 240 & $P_{36}:$ Ciecierski & 240 & 480 & $P_{49}:$ Klima & 50 & 100 \\
\hline$P_{11}:$ Goralski & 330 & 600 & $P_{24}:$ Schulz & 160 & 360 & $P_{37}:$ Cisowski & 240 & 480 & & & \\
\hline$P_{12}:$ Szumski & 360 & 600 & $P_{25}:$ Olesinski & 180 & 360 & $P_{38}:$ Borkowski & 240 & 480 & & & \\
\hline$P_{13}:$ Ploch & 240 & 480 & $P_{26}:$ Switała & 240 & 480 & $P_{39}:$ Banas & 180 & 360 & & & \\
\hline
\end{tabular}

Table 4. Adopted subjects $X$ allocation for FECS employees (file "X_base.xlsx" at https://github.com/erykszw/WEiI)

\begin{tabular}{|c|c|c|c|c|c|c|c|c|c|c|c|c|c|c|}
\hline$X$ & 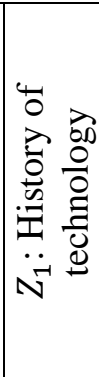 & 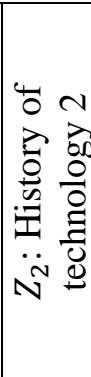 & 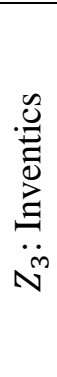 & 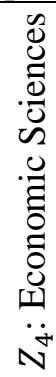 & 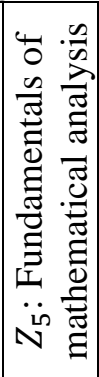 & 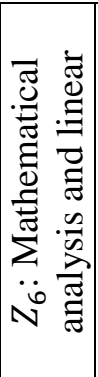 & $\vdots$ & 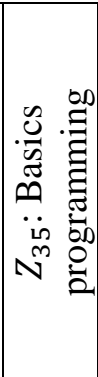 & 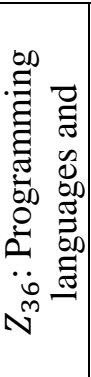 & $\vdots$ & $\vdots$ & 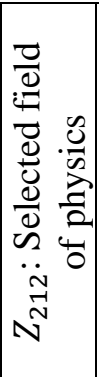 & 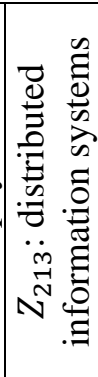 & 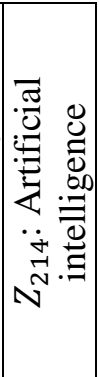 \\
\hline$P_{1}:$ Perz & 0 & 0 & 0 & 0 & 0 & 0 & $\ldots$ & 0 & 0 & $\ldots$ & $\ldots$ & 15 & 0 & 0 \\
\hline$P_{2}:$ Lejman & 0 & 0 & 0 & 0 & 0 & 0 & $\ldots$ & 90 & 90 & $\ldots$ & $\ldots$ & 0 & 0 & 0 \\
\hline$P_{3}:$ Matuszek & 0 & 0 & 0 & 0 & 0 & 0 & $\ldots$ & 60 & 0 & $\ldots$ & $\ldots$ & 0 & 0 & 0 \\
\hline$\ldots$ & $\ldots$ & $\ldots$ & $\ldots$ & $\ldots$ & $\ldots$ & $\ldots$ & $\ldots$ & $\ldots$ & $\ldots$ & $\ldots$ & $\ldots$ & $\ldots$ & $\ldots$ & $\ldots$ \\
\hline$P_{24}:$ Schulz & 15 & 0 & 0 & 0 & 0 & 0 & $\ldots$ & 0 & 0 & $\ldots$ & $\ldots$ & 15 & 0 & 0 \\
\hline$P_{25}:$ Olesinski & 20 & 15 & 0 & 0 & 0 & 0 & $\ldots$ & 0 & 0 & $\ldots$ & $\ldots$ & 0 & 0 & 0 \\
\hline$\ldots$ & $\ldots$ & $\ldots$ & $\ldots$ & $\ldots$ & $\ldots$ & $\ldots$ & $\ldots$ & $\ldots$ & $\ldots$ & $\ldots$ & $\ldots$ & $\ldots$ & $\ldots$ & $\ldots$ \\
\hline$P_{47}:$ Wingert & 0 & 0 & 0 & 45 & 0 & 0 & $\ldots$ & 0 & 0 & $\ldots$ & $\ldots$ & 0 & 0 & 0 \\
\hline$P_{48}:$ Tkacz & 0 & 0 & 0 & 0 & 0 & 0 & $\ldots$ & 0 & 0 & $\ldots$ & $\ldots$ & 0 & 0 & 0 \\
\hline$P_{49}:$ Klima & 0 & 0 & 0 & 0 & 0 & 0 & $\ldots$ & 0 & 0 & $\ldots$ & $\ldots$ & 0 & 0 & 0 \\
\hline
\end{tabular}

Using the data from Tables 1, 2, 3, 4, the competence framework $G_{O P T}$ is searched for, which guarantees full robustness $\left(R_{\omega}^{\lambda}=1\right)$ to absenteeism:

a) any single employee $(\omega=1)$,

b) any two employees $(\omega=2)$,

c) any three employees $(\omega=3)$.

For this purpose, an implementation of the method in the IBM ILOG CPLEX environment is used (calculations were performed on a computer equipped with an Intel i7-4770 processor and 8 GB RAM memory). The obtained solution shows the lack of a competence framework guaranteeing robustness $R_{\omega}^{\lambda}=$ 1 for each variant of absenteeism $\omega=1,2,3$. The maximum value of robustness is: $R_{1}^{0}=0.77, R_{2}^{0}=0.58$, $R_{3}^{0}=0.43$. Competence frameworks $G_{O P T}^{1}, G_{O P T}^{2}, G_{O P T}^{3}$ (superscript means the variant of absenteeism $\omega=$ 


\section{Issues in Information Systems}

Volume 22, Issue 1, pp. 188-199, 2021

$1,2,3)$ guaranteeing the aforementioned values of robustness $R_{\omega}^{\lambda}$ are presented in the file "Gopt1_Gopt2_Gopt3.xlsx" located at https://github.com/erykszw/WEiI.

The results obtained determine FECS's ability to replace absent employees. For example, the designated framework $G_{O P T}^{1}$ (138 new competencies) allows protecting FECS against the effects of $77 \%$ of possible scenarios of absenteeism of any single employee. Obtaining greater robustness is not possible. Making further changes in the competence framework does not improve its robustness (the obtained value $R_{1}^{0}=$ 0.77 is the robustness of the competence framework filled entirely with 1 values). The reason for this is due to restrictions on employee time limits. In this situation, you may consider hiring an additional employee. Therefore, the competencies that new employees should have been sought in order for the competence framework G guarantees $R_{\omega}^{\lambda}=1$ robustness in the event of $\omega$ employee absenteeism $(\omega=1,2,3)$.

The results are presented in the file "Gopt1_Gopt2_Gopt3_R=1.xlsx", located at https://github.com/erykszw/WEiI). Expected robustness $R_{\omega}^{\lambda}=1(\omega=1,2,3)$ is possible when the employed workers will have:

a) 21 competencies enabling the realization of subjects:

$Z_{4}, Z_{7}, Z_{23}, Z_{24}, Z_{25}, Z_{45}, Z_{93}, Z_{103}, Z_{114}, Z_{131}, Z_{132}, Z_{134}, Z_{135}, Z_{157}, Z_{158}, Z_{159}, Z_{160}, Z_{166}, Z_{168}, Z_{169}, Z_{170}$ (case $\omega=1)$

b) 71 competencies enabling the realization of subjects: $Z_{4}, Z_{5}, Z_{6}, Z_{7}, Z_{9}, Z_{10}, Z_{19}, Z_{21}, Z_{22}, Z_{23}, Z_{24}, Z_{25}, Z_{26}$, $Z_{27}, Z_{28}, Z_{29}, Z_{30}, Z_{34}, Z_{45}, Z_{51}, Z_{55}, Z_{56}, Z_{58}, Z_{77}, Z_{78}, Z_{79}, Z_{84}, Z_{86}, Z_{93}, Z_{99}, Z_{101}, Z_{102}, Z_{103}, Z_{104}, Z_{107}, Z_{111}, Z_{114}$, $Z_{115}, Z_{117}, Z_{120}, Z_{130}, Z_{131}, Z_{132}, Z_{133}, Z_{134}, Z_{135}, Z_{136}, Z_{137}, Z_{149}, Z_{153}, Z_{156}, Z_{157}, Z_{158}, Z_{159}, Z_{160}, Z_{161}, Z_{162}, Z_{164}$, $Z_{165}, Z_{166}, Z_{168}, Z_{169}, Z_{170}, Z_{179}, Z_{191}, Z_{196}, Z_{201}, Z_{203}, Z_{204}, Z_{208}, Z_{212}$ (case $\left.\omega=2\right)$,

c) 129 competencies (case $\omega=3$ ) - see $G_{O P T}^{3}$.

The obtained results show what competencies new employees should possess in order to protect FECS from the effects of all possible scenarios of employee absenteeism $(\omega=1,2,3)$. However, it should be noted that the number of employees to be hired is unknown. For example, in the case of $\omega=1$, for 21 competencies, it is possible to hire 21 new employees with one competence each. However, this is an unusual situation. Therefore, it is possible to hire one employee with all 21 competencies. As can be easily seen from the Figure 2, there are employees boasting a similar number of competencies in the competence framework. In the case of $\omega=2$, hiring an employee with the indicated 71 competencies is unlikely. However, it is possible to estimate the approximate number of employees required based on the average number of competencies per employee hired. The graph in the Figure 2 shows that, on average, one employee has 13.2 competencies.

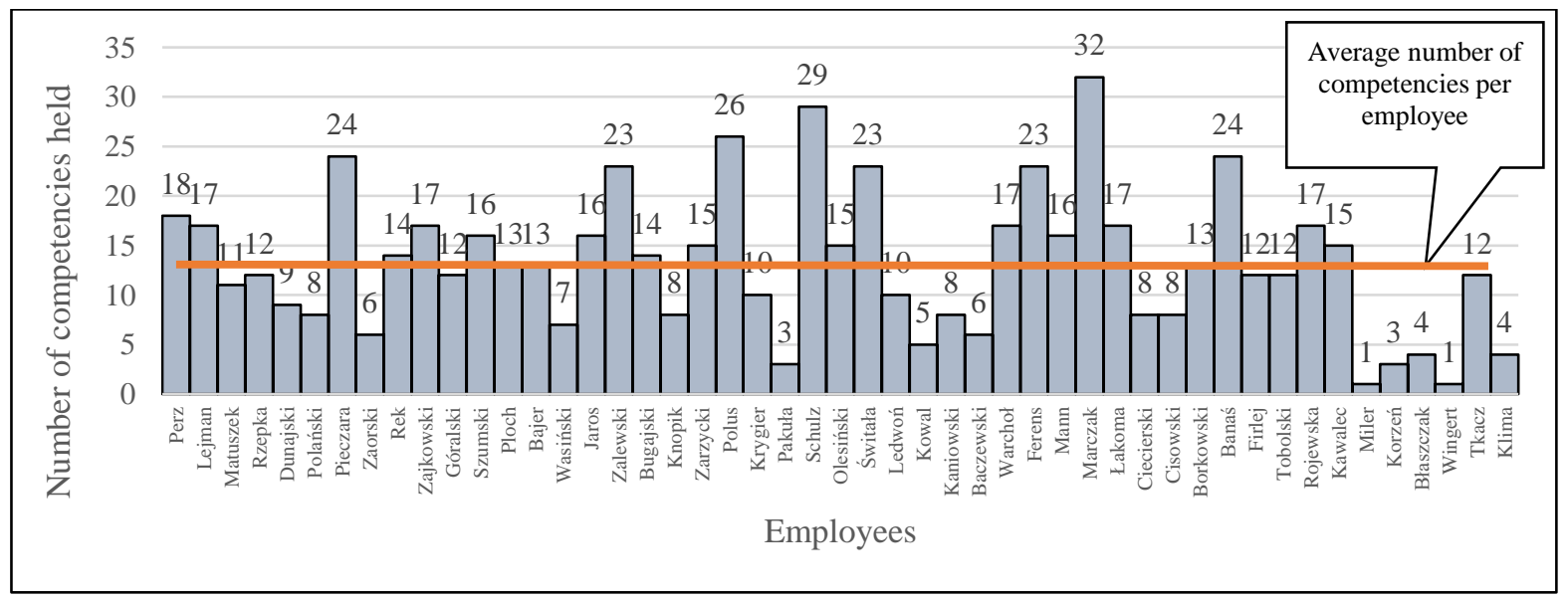

Figure 2. Number of competencies per employee 


\section{Issues in Information Systems}

Volume 22, Issue 1, pp. 188-199, 2021

Therefore, it can be concluded that:

a) in case of the absence of one employee $(\omega=1), 2$ new employees are needed to fill the missing 21 competencies,

b) in case of the absence of two employees $(\omega=2), 6$ new employees are needed to fill the missing 71 competencies,

c) in case of the absence of three employees $(\omega=3), 10$ new employees are needed to fill the missing 129 competencies.

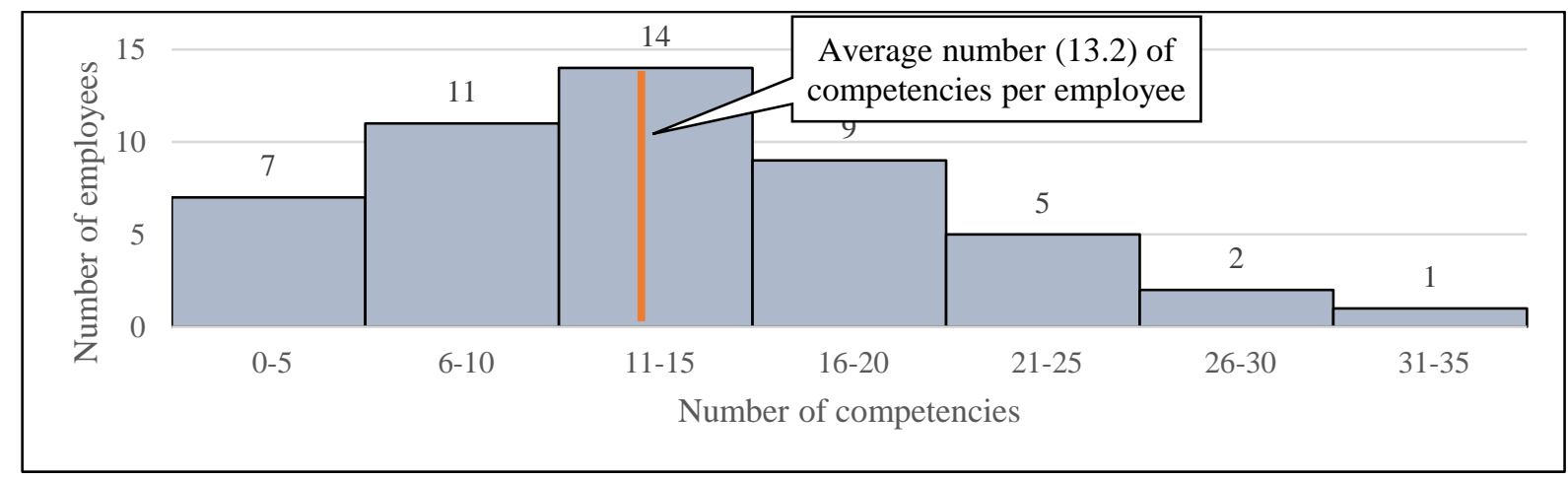

Figure 3. Number of employees with a certain number of competencies

In addition, from the histogram in the Figure 3, it can be observed that the most numerous, having between 11 and 15 competencies, is the group of 14 employees. This represents $28 \%$ of the hired employees. In turn: $22 \%$ of employees have between 6 and 10 competencies, $18 \%$ of employees have between 16 and 20 competencies, etc. Only $16 \%$ of employees have more than 20 competencies. Therefore, it can be assumed that by hiring 7 new employees with up to 20 competencies, robustness will be achieved for the case of the absence of three employees $(\omega=3)$.

\section{Conclusions}

Complementing the competencies of employees in accordance with the designated competence frameworks allows avoiding the consequences (e.g., loss of continuity in project realization) caused by employee absenteeism. The developed method is useful in the robustness assessment of the competence framework, synthesis of the competence framework guaranteeing a given robustness to given disruptions, synthesis of the competence framework of newly hired employees.

Implementation of the presented approach in HRMS/CMS class systems will enable early detection of needs and quick prototyping of alternative decisions in managing competencies of the employees. Such a solution will allow making personnel decisions while being forced by absenteeism and/or personnel fluctuation, legislative changes, modifications of the scope of orders, changes in customer requirements, etc.

In the future, it is planned to extend the model to:

- other types of disruptions encountered in practice, e.g., changes in the duration of activities, the occurrence of delays in the start/end of activities, etc.,

- stochastic and/or fuzzy data representations,

- assembling project teams with robust competence frameworks, 


\section{Issues in Information Systems}

Volume 22, Issue 1, pp. 188-199, 2021

Further research will also be directed towards the use of the method in the design processes of production systems, in which special attention is paid to employee substitutability translating into an increased level of system reliability (Gola, Pastuszak, Relich, Sobaszek \& Szwarc, 2021).

A topic worth considering in terms of future model modification is the assessment of the cost and time consumption of changes in the competence framework. The presented model assumes that the cost/time of each acquired competence is the same. By introducing appropriate cost and time parameters, it will become possible to search for such variants of competence frameworks that can also find their economic justification.

This work was financed by the "National Science Centre" under research project no. 2019/33/N/HS4/00379

\section{References}

Bocewicz, G., Szwarc, E., Wikarek, J., Nielsen, P., \& Banaszak, Z. (2021). A competency-driven staff assignment approach to improving employee scheduling robustness. Eksploatacja $i$ Niezawodnosc - Maintenance and Reliability, 23(1), 117-131.

Collier, Z.A., \& Lambert, J.H. (2018). Time Management of Infrastructure Recovery Schedules by Anticipation and Valuation of Disruptions. ASCE-ASME Journal of Risk and Uncertainty in Engineering Systems, Part A: Civil Engineering, 4(2).

Dück, V., Ionescu, L., Kliewer, N., \& Suhl, L. (2012). Increasing stability of crew and aircraft schedules. Transportation Research Part C: Emerging Technologies, 20(1), 47-61.

Gola, A., Pastuszak, Z., Relich, M., Sobaszek, Ł., \& Szwarc, E. (2021). Scalability analysis of reconfigurable manufacturing system's selected structures taking into account the reduction of reliability of technological machines. Eksploatacja i Niezawodnosc-Maintenance and Reliability, 23(2), 242-252.

Hom, P.W., Lee, T.W., Shaw, J.D., \& Hausknecht, J.P. (2017). One hundred years of employee turnover theory and research. Journal of Applied Psychology, 102(3), 530-545.

Ingels, J., \& Maenhout, B. (2015). The impact of reserve duties on the robustness of a personnel shift roster: an empirical investigation. Computers \& Operations Research 61, 153-169.

Ionescu, L., \& Kliewer, N. (2011). Increasing flexibility of airline crew schedules. Procedia - Social and Behavioral Sciences, 20, 1019-1028.

Klimek, M., \& Łebkowski, P. (2011). Resource allocation for robust project scheduling. Bulletin of the Polish Academy of Sciences: Technical Sciences, 59(1), 51-55.

Malen, J., \& Vaaler, P.M. (2017). Organizational Slack, National Institutions and Innovation Effort around the World. Journal of World Business, 52, 782-797.

Moudani, W., \& Mora-Camino, F. (2010). Solving crew reserve in airlines using dynamic programming approach. International Journal of Optimization: Theory, Methods and Applications, 2(4), 302329. 


\section{Issues in Information Systems}

Volume 22, Issue 1, pp. 188-199, 2021

Olivella, J., \& Nembhard, D. (2016). Calibrating cross-training to meet demand mix variation and employee absence. European Journal of Operational Research, 248, 462-472.

Söderholm, A. (2008). Project management of unexpected events. International Journal of Project Management, 26(1), 2008, 80-86.

Szwarc, E., Bocewicz, G., Bach-Dąbrowska, I., \& Banaszak, Z. (2019). Declarative Model of Competences Assessment Robust to Personnel Absence. In: R. Damaševičius, G. Vasiljevienè (Eds.), Information and Software Technologies - ICIST 2019. Springer, Cham, 12-23.

Szwarc, E., Bocewicz, G., Banaszak, Z., \& Wikarek, J. (2019). Competence allocation planning robust to unexpected staff absenteeism. Eksploatacja i Niezawodnosc - Maintenance and Reliability, 21(3), $440-450$.

Szwarc, E., Nielsen, I., Smutnicki, Cz., Bocewicz, G., Banaszak, Z., \& Bilski, J. (2020). Competenceoriented project team planning - university case study. Journal of Information and Telecommunication 2020.

Szwarc, E., Wikarek, J., Gola, A., Bocewicz, G., \& Banaszak, Z. (2020). Interactive Planning of Competency-Driven University Teaching Staff Allocation. Applied Sciences, 10(14).

Szwarc, E., \& Wikarek, J. (2020). Proactive planning of project team members' competences. Foundations of Management, 12(1), 71-84.

ec.europa.eu/eurostat/statistics-explained/index.php?title=Absences_from_work_-_quarterly_statistics (access date 30.01.2021) 